\title{
Long term bentonite erosion experiments in an artificial fracture: radionuclides mobility and diffusion in FEBEX bentonite
}

\author{
YASMINE Z KOUHAIL ${ }^{1}$, FRANZ RINDERKNECHT ${ }^{1}$, \\ FRANCESCA QUINTO ${ }^{1}$, VOLKER METZ ${ }^{2}$, THORSTEN \\ SCHÄFER $^{3}$ AND HORST GECKEIS ${ }^{4}$ \\ ${ }^{1}$ Karlsruhe Institute of Technology \\ ${ }^{2}$ Karlsruhe Institute of Technology (KIT) \\ ${ }^{3}$ Friedrich Schiller University Jena \\ ${ }^{4}$ Karlsruhe Institute of Technology (KIT), Institute for Nuclear \\ Waste Disposal (INE) \\ Presenting Author: yasmine.kouhail@kit.edu
}

Natural bentonite is envisaged to be used as engineered barrier for repositories of high-level radioactive waste in, e.g., crystalline rocks [1]. The intrusion of glacial melt water through fractures in host rock is expected to lead to the swelling and the erosion of the bentonite [3], with consecutive formation of bentonite colloids that would act as carrier for radionuclides, increasing their mobility. Therefore, there is a need to study the processes of radionuclide ( $\mathrm{RN}$ ) diffusion through the bentonite, bentonite erosion and the colloid-associated $\mathrm{RN}$ migration in order to assess its long-term barrier function.

FEBEX bentonite erosion experiments have been conducted in an artificial fracture set-up to simulate the intrusion of water in a repository. A ring of compacted bentonite (inner diameter of 40 $\mathrm{mm}$, outer diameter of $80 \mathrm{~mm}, 25 \mathrm{~mm}$ height) was emplaced between two Plexiglas plates spaced by a one $\mathrm{mm}$ height aperture to simulate a parallel fracture around the bentonite. Groundwater of the Grimsel Test Site, pumped through the fracture at a flow rate of $50 \mu \mathrm{L} / \mathrm{min}$, led to bentonite swelling and formation of a gel in the aperture [4]. Coarse grains of accessory minerals of various colors were visible in this gel and sampled for SEM-EDX, XRD and FTIR analysis.

In a similar experiment, Zn-labelled montmorillonite, a cocktail of radionuclide tracers (containing strongly sorbing ${ }^{241} \mathrm{Am}(\mathrm{III}),{ }^{137} \mathrm{Cs}(\mathrm{I}),{ }^{242} \mathrm{Pu}(\mathrm{IV})$, and weakly sorbing ${ }^{45} \mathrm{Ca}(\mathrm{II})$, $\left.{ }^{75} \mathrm{Se}(\mathrm{IV}),{ }^{99} \mathrm{Tc}(\mathrm{VII}),{ }^{233} \mathrm{U}(\mathrm{VI}),{ }^{237} \mathrm{~Np}(\mathrm{~V})\right)$ and a conservative tracer were mixed with a bentonite slurry and inserted in glass vials within the bentonite. In the effluent collected, analysis of colloids, elemental composition and radionuclide breakthrough were carried out. Furthermore, diffusion of the radionuclide tracers through the bentonite ring and their distribution in the bentonite gel will be investigated with (SF)ICP-MS and associated secondary mineral phases were identified. These results will allow for a comprehensive understanding of the mechanisms of radionuclide mobility through a geotechnical barrier.

References:

[1] Shelton et al., 2018. SKB Technical report TR-17-17

[2] Bouby et al., 2020. Appl. Clay Sci., 198_105797

[3] Rinderknecht, Doctoral thesis, KIT, $201 \overline{7}$

Acknowledgments: German Federal Ministry for Economic 